УДК 821.161.1

DOI 10.25205/1818-7919-2021-20-2-128-135

\title{
Мифопоэтика оборотня-дракона
}

\section{(«Путь дракона» Б. М. Юльского и литературный контекст)}

\section{Линь Гуаньцюн}

Московский государственный университет им. М. В. Ломоносова

Москва, Россия

\section{Аннотаичия}

Предмет анализа - функциональность мифологемы оборотня-дракона в рассказе русского писателя харбинской диаспоры Б. М. Юльского «Путь дракона» (1939). Мотивы повествования рассматриваются в контексте мифопоэтики оборотня-дракона, представленной в китайской, приамурской, славянской и европейской культурах: в славянской и европейской культурах образ дракона преимущественно отрицательный; в приамурской культуре дракон является священным символом; в китайской культуре он означает благополучие и власть. Доказано, что авторская интерпретация образа дракона объединяет восточную, русскую и европейскую традиции. Сюжет, изобразительные детали, узнаваемые реалии в рассказе отражают представления Б. М. Юльского об этноментальности китайцев, населявших территорию Дальнего Востока. Восприятие им этнического самосознания хунхузов, их ментального своеобразия, закрепленного в национальной мифологии, имеет реальную основу, что подтверждается положениями и выводами труда Д. В. Ершова «Хунхузы: необъявленная война. Этнический бандитизм на Дальнем Востоке» (2010). Сочетая принципы жизнеподобия и мифогенности, Б. М. Юльский создал специфическую фронтирную мифологию, выраженную в магическом сюжете рассказа. К трактовке произведения применены герменевтический и сопоставительный подходы. Привлечен китайский, приамурский, русский, европейский культурный материал, в том числе древний философский трактат «Хуайнаньцзы» (не позднее 139 г. до н. э.), китайский классический роман XVI в. «Путешествие на Запад», художественные произведения русских писателей «Фарфоровый павильон» (1918) и «Странник» (1918) Н. С. Гумилева, «Дракон» (1918) Е. И. Замятина, «Бронепоезд 14-69» (1921) Вс. В. Иванова, «Легенда о драконе» (1927) А. И. Несмелова, «Дракон» (<1930>) Вс. Н. Иванова, «Дракон, пожирающий солнце» (<1934>) Б. Н. Волкова, «Дракон» (1942-1944) Е. Л. Шварца, «Запахи миндаля» (1997) С. Г. Георгиева. Анализ художественной морфологии дракона опирается на произведения фольклора.

Ключевые слова дракон, оборотень, фронтирная мифология, харбинская диаспора, этнокультура

Благодарности

Работа выполнена при финансовой поддержке Государственного комитета КНР по управлению фондом обучения за границей

Для цитирования

Линь Гуаньиъюн. Мифопоэтика оборотня-дракона («Путь дракона» Б. М. Юльского и литературный контекст) // Вестник НГУ. Серия: История, филология. 2021. Т. 20, № 2: Филология. С. 128-135. DOI 10.25205/1818-79192021-20-2-128-135

\section{Mythopoetics of the Were-Dragon \\ (The Way of the Dragon by B. M. Yulsky and the Literary Context)}

\section{Lin Guanqiong}

Lomonosov Moscow State University

Moscow, Russian Federation

Abstract

As a Russian mountain-forest policeman and writer of the Harbin diaspora, B. M. Yulsky combined in his prose the experience of the police service and ideas about the ethnoculture of the Chinese who inhabited the territory of the Far 
East. This article contains a hermeneutic and comparative historical analysis of the short story The Way of the Dragon (1939) by B. M. Yulsky.

The artistic morphology of the dragon is built on the comparison of its image in Chinese, Amur, Slavic and European cultures. One of the key images in the Russian heroic epic, in the Christian legend of Saint George, in Western and Northern European mythology, the dragon is actualized in modern literature. The analysis involves a philosophical treatise and a Chinese classic novel. It is shown that in the Chinese mythopoetic consciousness the temper and morphology of the dragon is different from its interpretation in European and Russian texts.

The content of the short story by B. M. Yulsky speaks about his acquaintance with the understanding of the dragon, which is more characteristic in Chinese culture. The writer integrated the archaic image of the werewolf dragon into the real situation and brought a legend to the history of Honghuzi.

The facts set forth in the monograph by D. V. Ershov are the real confirmation of the story described by B. M. Yulsky. The Way of the Dragon is an example of the artistic ethnography and the authorial frontier mythology that have developed in Russian literature in Harbin.

Keywords

dragon, werewolf, frontier mythology, Harbin diaspora, ethnoculture

Acknowledgements

This work was funded by China Scholarship Council (CSC)

For citation

Lin Guanqiong. Mythopoetics of the Were-Dragon (The Way of the Dragon by B. M. Yulsky and the Literary Context). Vestnik NSU. Series: History and Philology, 2021, vol. 20, no. 2: Philology, p. 128-135. (in Russ.) DOI 10.25205/1818-7919-2021-20-2-128-135

\section{Введение}

В отличие от литературы западной ветви русского зарубежья, восточная ветвь литературы русского рассеяния пока изучена недостаточно. История русского зарубежья в Харбине не отличается длительностью, но отличается продуктивностью, поскольку были созданы многочисленные стихотворные и прозаические произведения с восточным колоритом. Среди писателей-харбинцев следует отметить Б. М. Юльского, который, с одной стороны, для своей прозы черпал материал из личного опыта службы в таежной полиции, с другой - обращался к этнокультуре китайцев. Оба источника способствовали художественному воссозданию этноментальности местного населения.

Рассказ Б. М. Юльского «Путь дракона», вошедший в состав цикла «Зеленая пустыня», впервые был опубликован в № 45 журнала «Рубеж» за 1939 г. Экспозицией служит повествование об экспедиции русской лесной полиции, продвигающейся по крутой сопке. Композиционно текст представляет собой рассказ в рассказе. Встреча взвода в полуразвалившейся фанзе со стариком-китайцем - отправная точка рассказанной им истории о метаморфозе человека в дракона. Легенда об оборотне-драконе формирует сюжет всего рассказа, мотивирует связь прошедшего и настоящего, показывает поэтическое сознание китайцев, объясняет специфику гидронима - расположенного рядом с фанзой соленого драконьего озера.

К анализу рассказа мы применяем герменевтический и сопоставительный подходы. Для выявления функциональности мифологемы оборотня-дракона в «Пути дракона» мы рассматриваем китайский, приамурский, славянский, европейский культурный материал, художественные произведения о драконе: «Дракон» (1942-1944) Е. Л. Шварца; «Дракон» (<1930>) Вс. Н. Иванова; «Дракон, пожирающий солнце» (<1934>) Б. Н. Волкова,; «Фарфоровый павильон» (1918) и «Странник» (1918) Н. С. Гумилева; «Бронепоезд 14-69» (1921) Вс. В. Иванова; «Запахи миндаля» (1997) С. Г. Георгиева; «Легенда о драконе» (1927) А. И. Несмелова; «Дракон» (1918) Е. И. Замятина; «Хуайнаньцзы» (не позднее 139 г. до н. э.); «Путешествие на Запад» (<90-е гг. XVI в.>). Мы привлекаем также научно-популярный труд Д. В. Ершова «Хунхузы: необъявленная война. Этнический бандитизм на Дальнем Востоке» (2010). Обращение к прозе Б. М. Юльского и обозначенному выше литературному и культурному контексту способствует понимаю этнокультуры, развившейся на территории совместного проживания русских и китайцев на Дальнем Востоке в первой половине ХХ в. 


\section{Литературный контекст}

Герой рассказа старого китайца - оборотень-дракон Лун. В славянской культуре дракон агрессивное чудовище, хищник, часто отождествляемый со змеей, противостоящий богатырям и угрожающий жизням обывателей. Самые известные варианты русского дракона Змий, Змей Горыныч, Тугарин Змеевич, Василиск. Дракон - один из ключевых образов в русском богатырском эпосе, в христианской легенде о Георгии Победоносце, в мифологии Западной и Северной Европы - актуализирован в новейшей литературе. Так, в пьесе-сказке «Дракон» Е. Л. Шварц использовал классический сюжет об убийстве рыцарем дракона и спасении прекрасной девушки: Ланцелот убивает трехголового Дракона-оборотня, который господствовал над городом четыреста лет, и тем самым спасает от него Эльзу; далее он решает убить дракона в душах горожан.

Ментально и по внешним характеристикам дракон в восприятии китайцев принципиально отличен от дракона в европейской мифологии. В облике европейского дракона, как правило, сочетаются пресмыкающееся и птица. Китайский дракон - без крыльев, с одной головой, длинным телом варана или ящерицы, он состоит из телесных элементов девяти животных: головы верблюда, рогов оленя, глаз кролика, шеи змеи, живота Шэна (морского чудовища, внешне похожего на крупную устрицу), чешуи карпа, лап тигра, когтей орла и ушей коровы. Он является национальным тотемом, китайцы считают себя его потомками. В отличие от европейской традиции, дракон в китайской культуре представляет собой символ благополучия и власти. Существует известная китайская идиома 望子成龙 ван изы чэн лун - «добиться успеха» (букв. «надеяться, что сын станет драконом»). Китайский дракон управляет водной стихией, может вызвать облака и дождь для обеспечения урожая. Поэтому он выступает «как воплощение положительного начала, как помощник, дающий воду и богатства» [Кириллова, 2015. С. 39]. С династии Хань (202 г. до н. э. - 220 г. н. э.), особенно с династии Сун (9601279) дракон стал монополистическим символом императора: «Абсолютно было запрещено, чтоб простые люди носили одежды с фигурами дракона. И из-за ношения таких одежд можно было подвергнуться смертной казни» [Юй Чуньбо, 2012. С. 117].

Сюжет о драконе в рассказе Б. М. Юльского имеет широкий литературный контекст. Русские писатели, обращаясь к китайской мифопоэтике, отступали от славянской интерпретации дракона, следовали китайской традиции. Среди исключений назовем «Дракона» Вс. Н. Иванова, который придает китайскому дракону морфологические черты европейского: «Тогда летали те грозящие драконы, / И знал китаец их на облаках огромных - / От дивных дней последний человек» [Русская поэзия Китая, 2001. С. 211]. Русские поэты проецировали на эмоциональное содержание произведений мысли и образы китайских авторов. Так, поэтэмигрант Б. Н. Волков подчеркивает созвучие своего «Дракона, пожирающего солнце» с китайской поэзией: «Ты поведал мне “Песни Дракона”, - / Так когда-то писал Ли-Чи» [Там же. С. 133]. Образ дракона в произведениях, имеющих отношение к китайским реалиям, наделен позитивной семантикой. Так, Н. С. Гумилев в «Фарфоровом павильоне» описывает друзей, пьющих вино «из чаш, расписанных драконами» [Гумилев, 1991. С. 227], тем самым лирический герой намекает на привилегированное положение своего окружения. В «Страннике» лирический герой, китаец, так тоскует по родине, что даже облако на небе выглядит как дракон, символизирующий Поднебесную: «Лишь увидя в небе облако, / Распластавшееся, как дракон» [Там же. С. 230]. В повести «Бронепоезд 14-69» Вс. В. Иванова китайский разведчик Син-Бин-У пел о том, что Красный Дракон и девушка Чен-хуа родили бунтующего русского. Здесь Красный Дракон символизирует Красную армию, преображающую Россию. Роман в коротких историях и притчах «Запахи миндаля» С. Г. Георгиева включает притчи о драконе. Например, в притче «Мгновение ока и три года» Дракон узнал, что если он пожжет все посевы, то бедняку Цу понадобится три года для их восстановления, и «убрался восвояси» - 
он «никогда не совершал бессмысленных поступков» ${ }^{1}$. В «Бое дракона с тигром» вся деревня наблюдала бой тигра с Драконом, и ученик Па Сюнь из-за этого даже опоздал на занятие. Святой дракон охраняет людей и обеспечивает урожай, поэтому люди рады его видеть и считают его появление счастливым знамением. Харбинец А. И. Несмелов в стихотворении «Легенда о драконе» объединяет западную и восточную традиции: «Из дыма их / На аспидные кручи, / Окрасив в пурпур / Блеклый небосклон, / Неслышно выполз / Сказочно могучий / Тысячекрылый / Огненный дракон» [Несмелов, 2006. С. 211]. Китайский дракон обычно появляется из дыма или облаков, тогда как огненный дракон с крыльями - образ, частый в западноевропейских и русских мифах.

В культуре коренных жителей Приамурья, граничащего с территорией Поднебесной, дракон также представляет собой священный символ. Солнечный дракон из мифов Приамурья посланник Солнца и созидатель Земли во время Всемирного потопа. Нанайский женский свадебный халат имеет узор «рыбья чешуя», на каждой чешуйке вышит дракон; считается, что таким образом дракон может обеспечить благополучие ее семьи и потомства.

В русской и китайской литературе оборотень-дракон редок, но встречается антропои зооморфный (по типу кентаврийского) образ дракона-человека. В рассказе Е. И. Замятина «Дракон» дракон-человек - циничный убийца интеллигента и жалостливый спаситель воробья ${ }^{2}$. В китайской литературе такая двойственность была обозначена уже в философском трактате «Хуайнаньцзы». В нем у бога Дракона-светильника «человеческое лицо, тело дракона и нет ног» [Земные формы, 2004. С. 83]. По китайскому преданию, «стоило ему [Дракону-светильнику. - Л. Г.] лишь приоткрыть их [глаза. - Л. Г.], как в мире наступал день, а когда он закрывал их, на землю спускалась ночь; стоило ему подуть, как появлялась пелена красных облаков, падал хлопьями обильный снег, и наступала зима; дыхнет - и тотчас красное солнце начинало палить, плавились металлы и камни, и наступало лето» [Юань Кэ, 1987. C. 31]. В космогонии роль Дракона-светильника схожа с миссией создателя Вселенной Пань-гу ${ }^{3}$.

\section{Мифопоэтика оборотня-дракона в «Пути дракона»}

В рассказе Б. М. Юльского «Путь дракона» образ оборотня-дракона актуализирован, он интегрирован в реальную современную ситуацию: 30 лет назад главарь шайки хунхузов, скрываясь от русского отряда, превратился в дракона. Его имя Лун - транскрибированный с китайского языка вариант, семантически обозначающий дракона. Поскольку дракон в китайской мифологии занимает центральное место, прозвище Лун указывает на исключительную роль героя в сообществе хунхузов. Характеристики дракона соответствуют китайским легендам: он не многоголовый, не огнедышащий и не имеет крыльев. По словам старика, Лун-дракон утонул в озере - «оно очень глубокое, никто не может достать дна» [Юльский, 2011. С. 31], что отвечает китайским мифопоэтическим представлениям, согласно которым дракон обычно живет в воде и управляет водной стихией ${ }^{4}$. Например, в китайском классическом романе «Путешествие на Запад» присутствуют цари-драконы четырех морей и царьдракон реки Цзин.

Лун-хунхуз из рассказа Б. М. Юльского представляет собой угрозу населению: «Каждый год после сбора посевов он брал с крестьян налог» [Там же], потому русский командир полу-

\footnotetext{
${ }^{1}$ Георгиев С. Г. Мгновение ока и три года // Георгиев С. Г. Запахи миндаля. URL: https://myrt.ru/read/426146zapahi-mindalya.html (дата обращения 31.07.2020)

2 «Метафора “дракон с винтовкой” имеет обобщенный политический смысл, она указывает на ожесточенность участвующего в революции народа и его неприязнь к интеллигенции», «“органический” человек показан здесь также неоднозначно» [Давыдова, 2018. С. 139].

${ }^{3}$ Пань-гу - мифический первопредок в древнекитайской мифологии, первый человек на земле. Мифы о Паньгу зафиксированы письменно в ІІІ в. н. э. Его главный подвиг - сотворение мира: его дыхание стало ветром, голос - громом, глаза - солнцем и луной, кровь - реками и т. д.

4 Дракон «в представлениях ранних государств», в том числе Китая, связан с «культом водоемов» [Иванов, 1980. С. 394].
} 
чает приказ либо взять его живым, либо привезти его голову. Лун-дракон - не грабитель; он, подобно Дракону-светильнику («Хуайнаньцзы»), совершает акт творения. Сюжет о превращении человека в дракона трансформируется в сюжет об обустройстве пространства. Дракон покрыт чешуей, у него зубчатая спина, когтистые лапы, и автор придает пейзажу зооморфные черты: «Дорожка тянется по узкому, как лезвие ножа, гребню, извиваясь в стороны, поднимаясь и спускаясь. Ее изгибы напоминают ползущую змею. По обеим сторонам - крутые, почти отвесные склоны» [Юльский, 2011. С. 29-30]; хребет сопки «оканчивается внезапно крутым ребристым склоном, и тропа сбегает по нему вниз» [Там же. С. 30]. Приведенный пейзаж схож с созданным Вс. Н. Ивановым образом дракона, «извившегося своею узкой тушей» [Русская поэзия Китая, 2001. С. 211]. Из рассказа старика русские узнают, как был ранен дракон, как брызги крови превращались в алые цветы, как кровь посолила воду в озере. Пейзажные описания обрамляют сюжет о драконе.

В рассказе старика звучит мотив отшельничества, характерный для китайской, особенно даосской литературы: дракон утонул, он изолирован от внешнего мира, что соотносится с историей старика, живущего уединенно. Вместе с тем природа как пространственный аналог дракона являет собой его воплощение, описана как хтоническое существо.

Итак, в образе оборотня-дракона Б. М. Юльский сочетал, с одной стороны, восточную и, с другой - европейскую, русскую литературные традиции: оборотень-дракон имеет китайское имя Лун, его морфологическая характеристика отвечает образу дракона в китайской мифологии, но его грабительский образ жизни мы рассматриваем как отступление от ее сюжетов. «Заслугой Юльского следует признать обращение к региональному материалу, который зачастую игнорировали молодые харбинские литераторы, всеми своими помыслами обращенные к литературе западного зарубежья, к “парижской ноте”» [Иващенко, 2006. С. 107]. Справедлив вывод Е. О. Кирилловой о том, что в произведениях Б. М. Юльского, напротив, проявляется переплетение культурных пространств Востока и Запада [Кириллова, 2016].

В рассказе Б. М. Юльский совместил два плана повествования - реальный и мифологический. Понятие «путь», обозначенный в названии рассказа, служит ключом к повествованию, в том числе к пониманию структуры мотивов. Во-первых, путь - это реальный, узнаваемый путь, проходящий на территории совместного проживания русских и китайцев на Дальнем Востоке; по нему продвигается русская лесная полиция. Во-вторых, название рассказа коррелирует с мотивом пути на крутой сопке, по которому 30 лет назад убегал оборотень-дракон Лун. В-третьих, лексемой «путь» автор обозначил историю жизни Луна, рассказанную стариком-китайцем. Русский командир взвода, «немного мечтатель и лирик в душе» [Юльский, 2011. С. 33], высказывает предположение о том, что старик - «этот самый Лун, который спасался от русских» [Там же]. Таким образом, Б. М. Юльский расширяет семантику слова «путь» до обозначения судьбы рассказчика-старика.

\section{Реальная основа повествования}

Отметим, что в 1938-1941 гг. Б. М. Юльский работал в горно-лесной полицейской службе, и это помогло ему познакомиться с тайгой, с местными жителями на границе КВЖД. Детали, соотнесенные с рассказом о Луне, имеют реальную основу. В научно-популярном труде Д. В. Ершова «Хунхузы: необъявленная война. Этнический бандитизм на Дальнем Востоке» зафиксирован факт, коррелирующий с именем героя Юльского: «благодаря своим качествам бойца и лидера» [Ершов, 2010. С. 23] пленник-японец Кохината Хакуро стал атаманом хунхузов, и «местное население наградило его прозвищем Сяо Байлун (Маленький Белый Дракон)» [Там же. С. 24]. Рассказ старика о происхождении красных цветов соотнесен с маковым полем недалеко от драконова озера. Как отмечает Д. В. Ершов, «одним излюбленным занятием хунхузов было выращивание опийного мака и контрабанда опиума $<\ldots>$ Ocновными поставщиками опиума на севере Китая, а также на российском Дальнем Востоке в конце XIX столетия стали “краснобородые" [хунхузы. - Л. Г.]» [Там же. С. 31]. Командир взвода лесной полиции не исключает того, что маковое поле принадлежит старику. Хунхузу, 
принятому русскими за сборщика женьшеня или зверолова, с помощью легенды о драконе удалось придать реальному месту табуированный колорит, ввести русских в заблуждение, но и расположить к себе: командир принимает решение не уничтожать маковое поле ${ }^{5}$. В отличие от западной ветви русской эмиграции, русских писателей харбинской эмиграции окружала дикая природа. По мнению А. А. Забияко, Дж. Лондон дал им ориентир для развития прозы «художественной этнографии»: «Сама географическая, этнокультурная и социокультурная ситуация, в которой они оказались, поощряла пассионарность, жажду приключений и подвига, стимулировала в литературной среде интерес к экзотической природе и ее обитателям» [Забияко, 2015. С. 93].

\section{Заключение}

Таким образом, создавая авторскую фронтирную мифологию, Б. М. Юльский, в большей мере ориентируясь на китайскую традицию, описал этноментальность китайцев, населявших территорию совместного проживания русских и китайцев на Дальнем Востоке. Изображая реалии местности, он стер границу между жизнеподобием и мифом, создал магическую историю ${ }^{6}$, в которой персонажи находятся на грани факта и легенды.

\section{Список литературы}

Гугнин А. А. Магический реализм // Литературная энциклопедия терминов и понятий / Под ред. А. Н. Николюкина. Ин-т научной информации по общественным наукам РАН. М.: Интелвак, 2001. Ст. 489-492.

Гумилев Н. Фарфоровый павильон // Гумилев Н. Соч.: В 3 т. / Вступ. ст., сост., примеч. Н. А. Богомолова. М.: Худож. лит., 1991. Т. 1: Стихотворения. Поэмы. С. 227-259.

Давыдова Т. Т. Замятинская энциклопедия. М.: Флинта, 2018. 744 с.

Ершов Д. В. Облик дракона. Кто такие хунхузы? // Ершов Д. В. Хунхузы: необъявленная война. Этнический бандитизм на Дальнем Востоке: Монография. М.: Центрполиграф, 2010. C. 9-38.

Забияко А. А. Проза харбинского писателя Бориса Юльского в контексте художественной этнографии дальневосточного зарубежья // Гуманитарные исследования в Восточной Сибири и на Дальнем Востоке. 2015. № 2. С. 91-102.

Земные формы // Философы из Хуайнани. Хуайнаньцзы / Пер. с кит. Л. Е. Померанцевой; сост. И. В. Ушаков. М.: Мысль, 2004. С. 75-86.

Иванов В. В. Дракон // Мифы народов мира: В 2 т. / Гл. ред. С. А. Токарев. М.: Сов. энциклопедия, 1980. Т. 1. С. 394-395.

Иващенко Е. Г. «Утраченные иллюзии» Бориса Юльского // Русский Харбин, запечатленный в слове: Сб. науч. работ преподавателей и студентов кафедры русской филологии АмГУ / Под ред. А. А. Забияко, Е. А. Оглезневой. Благовещенск: Амур. гос. ун-т, 2006. C. $105-127$.

Кириллова Е. О. Ориентальные темы, образы, мотивы в литературе русского зарубежья Дальнего Востока (Б. М. Юльский, Н. А. Байков, М. В. Щербаков, Е. Е. Яшнов): Монография. Владивосток: Изд-во ДВФУ, 2015. 276 с.

Кириллова Е. О. Переплетение культурных пространств Востока и Запада в творчестве писателя русского зарубежья Б. Юльского // Вестник Череповец. гос. ун-та. 2016. № 5 (74). C. $81-89$.

Несмелов А. Легенда о драконе // Несмелов А. Собр. соч.: В 2 т. / Сост. Е. Витковский, А. Колесов, Ли Мэн, В. Резвый. Владивосток: Альманах «Рубеж», 2006. Т. 1: Стихотворения и поэмы. С. 210-212.

\footnotetext{
${ }^{5}$ Главной задачей лесной полиции являлась борьба с хунхузами [Смирнов, 2012. С. 22-23].

${ }^{6}$ Согласно А. А. Гугнину, эпитет «магический», «наряду с первичной, видимой, реальностью, включал в себя вторую, загадочную и необъяснимую, скрытую от наивного взгляда сторону действительности, которую писатель должен был обнаружить и “реалистически” изобразить в своем произведении» [Гугнин, 2001. Ст. 489].
} 
Русская поэзия Китая: Антология / Сост. В. Крейд, О. Бакич. М.: Время, 2001. 720 с.

Смирнов С. В. Предыстория русских воинских отрядов // Смирнов С. В. Отряд Асано: русские воинские формирования в Маньчжоу-го, 1938-1945: Монография. Екатеринбург: Изд-во УрГУ, 2012. С. 8-27.

Юань Кэ. Как создавался мир // Юань Кэ. Мифы древнего Китая: Монография / Пер. с кит., послесл. Б. Л. Рифтина. М.: Наука, 1987. С. 28-58.

Юй Чуньбо. Образ дракона в культурах Китая и России // Современные гуманитарные исследования. 2012. № 1 (44). С. 117-120.

Юльский Б. Путь дракона // Юльский Б. Зеленый легион: повесть и рассказы / Сост. А. Колесова, А. Лобычева; вступ. ст. А. Лобычева; коммент. А. Колесова. Владивосток: Альманах «Рубеж», 2011. С. 29-34.

\section{References}

Davydova T. T. Zamyatinskaya entsiklopediya [Zamyatin's Encyclopedia]. Moscow, Flinta Publ., 2018, 744 p. (in Russ.)

Ershov D. V. Oblik drakona. Kto takie khunkhuzy? [The Dragon Form. Who are Honghuzi?]. In: Ershov D. V. Khunkhuzy: neob"yavlennaya voina. Etnicheskii banditizm na Dal'nem Vostoke [Honghuzi: Undeclared War. Ethnic Banditry in the Far East]. Moscow, Tsentrpoligraf Publ., 2010, p. 9-38. (in Russ.)

Gugnin A. A. Magicheskii realizm [Magical Realism]. In: Literaturnaya entsiklopediya terminov i ponyatii [Literary Encyclopedia of Terms and Concepts]. Moscow, Intelvak Publ., 2001, p. 489-492. (in Russ.)

Gumilev N. Farforovyi pavil'on [Porcelain Pavilion]. In: Gumilev N. Sochineniya [Compositions]: In 3 vols. Moscow, Khudozhestvennaya literatura Publ., 1991, vol. 1, p. 227-259. (in Russ.)

Ivanov V. V. Drakon [Dragon]. In: Mify narodov mira [Myths of the Peoples of the World]: In 2 vols. Moscow, Sovetskaya entsiklopediya Publ., 1980, vol. 1, p. 394- 395. (in Russ.)

Ivashchenko E. G. "Utrachennye illyuzii" Borisa Yul'skogo [Boris Yulsky's "Lost Illusions"]. In: Russkiy Kharbin, zapechatlennyi v slove: Sb. nauch. rabot prepodavatelei i studentov kafedry russkoi filologii AmGU [Collection of Scientific Works of the Teachers and Students of the Department of Russian Philology of AmSU]. Blagoveshchensk, Amur State Uni. Publ., 2006, p. 105-127. (in Russ.)

Kirillova E. O. Oriental'nye temy, obrazy, motivy v literature russkogo zarubezh'ya Dal'nego Vostoka (B. M. Yulsky, N. A. Baikov, M. V. Shcherbakov, E. E. Yashnov) [Oriental Themes, Images, and Motives in the Literature of the Russian Far East Diaspora (B. M. Yulsky, N. A. Baykov, M. V. Shcherbakov, E. E. Yashnov)]. Vladivostok, Dal'nevostochnyi federal'nyi universitet Publ., 2015, 276 p. (in Russ.)

Kirillova E. O. Perepletenie kul'turnykh prostranstv Vostoka i Zapada v tvorchestve pisatelya russkogo zarubezh'ya B. Yul'skogo [The Interweaving of the Cultural Spaces of the East and the West in the Work of the Writer of the Russian Emigration B. Yulsky]. Vestnik Cherepovetskogo gosudarstvennogo universiteta [CHSU Bulletin], 2016, no. 5(74), p. 81-89. (in Russ.)

Nesmelov A. Legenda o drakone [The Legend about the Dragon]. In: Nesmelov A. Collected Works. In 2 vols. Vladivostok, Al'manakh "Rubezh” Publ., 2006, vol. 1, p. 210-212. (in Russ.)

Russkaya poeziya Kitaya: Antologiya [Russian Poetry of China: Anthology]. Moscow, Vremya Publ., 2001, 720 p. (in Russ.)

Smirnov S. V. Predystoriya russkikh voinskikh otryadov [The Prehistory of Russian Military Detachments]. In: Smirnov S. V. Otryad Asano: russkie voinskie formirovaniya v Man'chzhougo, 1938-1945 [Asano Detachment: the Russian Military Formations in Manchukuo, 19381945]. Ekaterinburg, Ural State Uni. Press, 2012, p. 8-27. (in Russ.) 
Yu Chunbo. Obraz drakona v kul'turakh Kitaya i Rossii [The Image of the Dragon in Chinese and Russian Cultures]. Sovremennye gumanitarnye issledovaniya [Modern Humanities Studies], 2012, no. 1 (44), p. 117-120. (in Russ.)

Yuan Ke. Kak sozdavalsya mir [How the World Was Created]. In: Yuan Ke. Mify drevnego Kitaya [Ancient Chinese myths]. Moscow, Nauka, 1987, p. 28-58. (in Russ.)

Yulsky B. Put' drakona [The Way of the Dragon]. In: Yulsky B. Zelenyi legion: povest' i rasskaz [The Green Legion: Story and Short Stories]. Vladivostok, Al'manakh "Rubezh" Publ., 2011, p. 29-34. (in Russ.)

Zabiyako A. A. Proza kharbinskogo pisatelya Borisa Yul'skogo v kontekste khudozhestvennoi etnografii dal'nevostochnogo zarubezh'ya [The Prose of the Harbin Writer Boris Yulsky in the Context of the Artistic Ethnography of the Far East Diaspora]. Gumanitarnye issledovaniya $v$ Vostochnoi Sibiri i na Dal'nem Vostoke [Humanities Researches in Eastern Siberia and the Far East], 2015, no. 2, p. 91-102. (in Russ.)

Zemnye formy [Earthly Forms]. In: Filosofy iz Khuainani. Khuainan'tszy [Philosophers from Huainan. Huainanzi]. Moscow, Mysl’ Publ., 2004, p. 75-86. (in Russ.)

$$
\begin{array}{r}
\text { Материал поступил в редколлегию } \\
\text { Received } \\
01.08 .2020
\end{array}
$$

\section{Сведения об авторе}

Линь Гуаньцюн, аспирант кафедры истории новейшей русской литературы и современного литературного процесса филологического факультета Московского государственного университета им. М. В. Ломоносова (Москва, Россия)

linguantsyun@mail.ru

\section{Information about the Author}

Lin Guanqiong, PhD student of the Department of History of Modern Russian Literature and Contemporary Literary Process of Faculty of Philology of Lomonosov Moscow State University (Moscow, Russian Federation)

linguantsyun@mail.ru 